\title{
Application of Site-Specific Hazard Assessment Testing to Solid Wastes
}

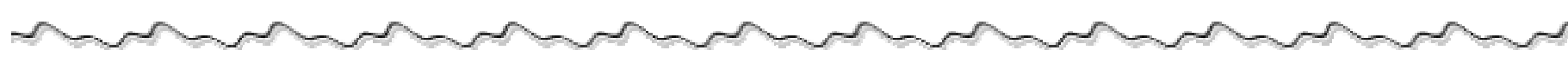

\author{
G.F. Lee and R. A. Jones
}

ABSTRACT: The U.S. Environmental Protection Agency (U.S. EPA) proposes to use a leaching test as one of the criteria for estimating the environmental hazard of on-land disposal of hazardous wastes. There are many significant technical problems with the specific protocols proposed for use, such as not specifying a defined redox condition under which the tests are to be conducted. The most significant deficiency is in the proposed method for interpretation of leaching test results. The use of these tests as currently formulated could readily result in chemicals that present minimal risk to the environment and human health being classified as hazardous. More importantly, their use could cause truly hazardous wastes to be classified as acceptable for on-land disposal with minimum restrictions. Adopting the U.S. EPA's proposed approach will result in unnecessarily large amounts of money being spent for control of "hazardous" chemicals and, in certain cases, without providing adequate environmental or human health protection.

This paper reviews some of the problems associated with the use of the U.S. EPA Resource Conservation and Recovery Act (RCRA) leaching test for classifying the hazardous nature of chemicals destined for land disposal. Recommendations are made for modification of the RCRA leaching test, to provide for a site-specific evaluation procedure to more properly evaluate the potential hazard associated with on-land disposal of hazardous wastes. An approach is discussed which combines environmental physics (transport and mixing), chemistry-fate, and biology (toxicology, bioconcentration) information. This approach is presented as a basis for interpretation of the results of the leaching tests in terms of the hazard associated with the disposal of a particular waste at a particular site. This "hazard assessment approach," which has been adapted for application to solid wastes by the authors, is a sequential, selective test in interpretation scheme for combining information on environmental physics (transport and mixing), chemistry-fate, and biology (toxicology and bioconcentration) of a waste and disposal site to determine potential environmental hazard.

KEY WORDS: hazard assessment, leaching test, hazardous waste

It has been known for many years that the potential environmental hazard of contaminants associated with solids, such as those in municipal and industrial wastes, cannot be judged, as has been attempted in the past, based on the total content of a particular contaminant within the solid. Therefore, the U.S. Environmental Protection Agency (U.S. EPA), through the Resource Conservation and Recovery Act (RCRA), has been attempting to develop a more technically valid, cost-effective approach to assessing the potential environmental hazard of solids-associated contaminants. RCRA specifies that solid wastes be classified according to their potential environmental hazards, and be disposed of in a manner acceptable for their classifications. There is considerable 
controversy, however, about the validity of the U.S. EPA's approach, which advocates classifying the toxicity of wastes based on the concentrations in the leachate from its leaching test. ${ }^{2}$ As outlined presently, the U.S. EPA's toxicity classification is established by comparing the leachate concentrations with arbitrarily established concentration limits for the same. Many individuals who are familiar with interactions between contaminants and solids and with the impact of foms of contaminants on beneficial uses of the environment, recognize that such a procedure is technically invalid. They also recognize that such a requirement may cause massive expenditures of private and public funds for contaminant control, yet would not provide dependable or predictable environmental protection. Because of the many technical problems with the current leaching test, the restrictions it could lead to may be overly stringent. Further, for certain circumstances, the public might be given inadequate protection because a particular waste disposed of in a certain way could be a real hazard in the environment, yet be classified as nonhazardous based on results of the RCRA leaching test.

Shortly after RCRA regulations were first proposed and several years before final adoption, Lee [1]3 commented on the inadequacies of draft extraction procedures proposed in the Federal Register. He pointed up that the procedure as initially proposed, which is similar in many respects to the one that was finally adopted, could not reliably accomplish the U.S. EPA's stated objectives for it. Lee and Jones [2] have provided a detailed discussion of the problems with the current extraction procedure as being used by the U.S. EPA and with the implementation of the provisions of RCRA. The fundamental problem with the U.S. EPA's required testing procedure is that it fails to take into account adequately properties of disposal sites, characteristics of interactions between chemical contaminants and solids, or the impact of contaminants on water quality.

Concurrent with the U.S. EPA's activities in this matter, an American Society for Testing and Materials (ASTM) committee, which has since become Committee on Waste Disposal. has been attenipting to develop batch extraction procedures-leaching tests to improve on the U.S. EPA's extraction procedure. As discussed by Lee [3], however, this procedure has essentially the same fundamental deficiencies as the U.S. EPA extraction procedure, and also cannot yield results that can be used to characterize properly the potential environmental hazards associated with contaminants in solid wastes. Although ASTM Committee D34 is beginning to develop a range of tests to supplement its batch extraction procedure, in the opinion of the authors both the U.S. EPA-RCRA group and ASTM Committee D34 should reevaluate and extensively revise their leaching testsextraction procedures, such that they can be reliably adapted for use on a wide variety of wastes to implement technically valid, cost-effective, yet environmentally protective solid waste evaluation and management programs.

\section{Previous Experience in Developing Leaching Tests}

A problem similar to the assessment of the hazards associated with solid wastes has been faced over the past several years with the development and evaluation of the elutriate test for estimating the potential for the release of dredged sediment-associated contaminants 
during dredging and dredged sediment disposal in open water and on-land systems. In the late 1960s, it became recognized that many of the sediments of U.S. waterways requiring periodic dredging to keep them navigable. contained concentrations of a wide variety of chemical contaminants, which, if released in sufficient amounts of available forms, could have significant detrimental effects on the beneficial uses of dredging or disposal-area waters. It has been known for many years [4] that one of the primary factors controlling the release of many contaminants from aquatic sediments is the physical mixing of the sediments with water. The dredging-disposal process typically incorporates such a mixing; in hydraulic dredging. the sediments are slurried with waters of the region, and either pumped or transported by boat to a new location for disposal. The dredging action in many cases is similar to what occurs under high flow conditions in rivers or under storm conditions in lakes, in which large amounts of sediment are suspended into the water column, thereby providing more optimum conditions for exchange of contaminants with the water.

As part of the U.S. Army Corps of Engineers Dredged Material Research Program (DMRP), the authors were involved in a large scale. multifaceted study directed toward developing and evaluating the applicability of the elutriate test. This testing procedure, after which the hazardous waste leaching test developed by the U.S. EPA- RCRA was patterned, involves mixing one part of dredged sediment with four parts of water from the area for a period of $30 \mathrm{~min}$, allowing the sediment/water mixture to settle for $1 \mathrm{~h}$. filtering the supernatant through a $0.45 \mathrm{~mm}$ pore size membrane filter. and measuring the release of contaminants in the "elutriate." or filtered supernatant. The elutriation procedure specifications were designed to imitate in the laboratory. conditions expected at open water disposal areas for hydraulically dredged sediments. In part, the studies done in developing and refining the elutriate test consisted of collecting samples of waterway sediments from a wide variety of locations throughout the United States, subjecting them to the elutriate test, and determining the release of about 30 different contaminants. The test conditions, such as liquid-to-solid ratio, $\mathrm{pH}$, type (source) of water, degree of agitation, redox conditions, etc. were varied in some tests to determine if the test conditions themselves substantially affected contaminant release.

In order for a leaching test to be a reliable test, the results should be reasonably insensitive to minor variations of test conditions. Studies by Lee et al. [5] and Jones and Lee [6] have shown that in general, results of the elutriate test, as originally formulated by the U.S. EPA and the Corps of Engineers, are relatively insensitive to certain parameters, such as source of water. However, the results are highly impacted by the oxidation-reduction conditions that exist within the test system. As discussed by Jones and Lee [6], this is to be expected. based on the aqueous environmental chemistry of iron. Because of its "scavenging" action, the oxidized form of iron causes many contaminants that would be released under reducing conditions, to show no release, or release and subsequent sorption-uptake under oxic conditions. Therefore. it is important that the oxidation-reduction conditions prevailing during the test be defined and controlled, since for many contaminants. what is released under anoxic test conditions has no relationship to what would be found when dredged sediment is disposed of in oxic waters. 
The second and most important phase of the evaluation of the elutriate test for dredged sediments was the comparison of predicted contaminant release in elutriate tests with actual release during dredged material disposal operations. About 20 field studies were conducted at various locations in the United States, in which sediments which were to be dredged were subjected to the elutriate test. In conjunction with this, at the time the dredging-disposal took place, detailed field studies were conducted to determine the actual release of contaminants from these sediments to the disposal site water column. A thousand or so water samples were collected in the disposal area before, during, and over time following the disposal to determine the magnitude of release and the persistence of the chemicals that were released. As discussed by Lee et al. [5] and Jones and Lee [6] it was found that there was remarkably good agreement between the direction and the approximate magnitude of release found in the elutriate tests and what was observed in the field during actual dredged material disposal operations. Based on these results, it is possible to have some confidence that the elutriate test is a useful tool for predicting the potential hazard of various types of chemicals associated with dredged sediment to beneficial uses of water in the region of the dredged material disposal site. It is important to note, however, than in using elutriate test results to assess the potential environmental impact of dredged sediment disposal, factors independent in addition to the concentration of contaminants in an elutriate must he considered. Jones and Lee [6] discuss how the results of the elutriate tests should be used to assess potential adverse impacts.

The same kind of evaluation program needs to be conducted for the hazardous waste leaching test as was conducted for the dredged sediment elutriate test. However, because of the greater variety of disposal situations and contaminants encountered with hazardous waste disposal, a much more extensive study will have to be conducted. It is estimated that the Corps of Engineers' study in the mid-1970s on the elutriate test cost between $\$ 1$ and $\$ 1.5$ million over about a five-year period. It will take probably between $\$ 5$ and $\$ 10$ million in research efforts, over a 5 to 10 year period, to develop and substantiate the applicability-usability of a leaching test for hazardous wastes that has some predictive capability for assessing the potential hazard that a contaminant present in a solid waste may represent to the environment in the region in which the disposal takes place.

\section{Suggested Approach for Developing Hazardous Waste Leaching Test}

\section{General Considerations}

Because any leaching test developed for evaluating solid waste-associated contaminants reduces a complex environmental system to a simple laboratory one, extreme care must be taken to ensure that the most significant characteristics of the field are appropriately accounted for in laboratory testing. Even when this is done, the results of the leaching test are, to some extent, operationally-defined; the test must be viewed and results interpreted in light of this.

This first phase of the development of such a laboratory test is to clearly define the objective or the purpose of the test. In the case of hazardous wastes, the primary question that must be answered by a leaching test is, how much and at what rate will contaminants 
associated with a particular solid waste be released in a particular disposal operation. Since the tendency for a contaminant to be released from a particular solid is governed by many different, rather poorly defined factors, the importance of which are highly sitespecific, it is technically invalid to follow the approach of the U.S. EPA-RCRA regulations of using one set of test conditions for all situations. Instead of trying to specify a single test condition, the U.S. EPA should have developed general guidelines to establish the appropriate test conditions for each site to be evaluated, to account for those waste and disposal area characteristics of importance. Those responsible for generation of the waste or its disposal, or both. Should have the responsibility or share the responsibility for conducting an appropriate leaching test applicable to the particular type or types of contaminant associated with the particular type of solid disposed of in a certain manner.

While site-specific approaches of this type have been somewhat uncommon in the water pollution control field in the past, the field is advancing, and such approaches are becoming part of the standard procedures for assessing the significance of contaminants in impairing beneficial uses of a particular water. The changes in the field can be exemplified by the U.S. EPA Water Quality Criteria and Standards branch. For many years this branch encouraged states to adopt single-value, numeric standards for contaminants which would be applicable to all state waters. While the U.S. EPA's worst case water quality criteria were developed in accordance with the provisions of Public Law 92-500, to be used as a basis for developing state water quality standards, according to U.S. EPA policy these criteria were to be used directly as water quality standards. Many states have chosen not to adopt numeric standards because it is well known that single value, worst case, numeric standards are not cost-effective and are often excessively stringent. The U.S. EPA Water Quality Criteria and Standards branch, for the first time, after much urging by experts in the water quality field, is now developing what are being called "site-specific criteria." However, it remains to be seen how these criteria will be developed and implemented into standards.

Water quality evaluation and management programs developed have typically been the result of trade-offs between regulatory simplicity (that is, ease of administration) and technical validity. In the early 1970s, the U.S. Congress passed regulations outlining the minimum treatment goals for contaminants associated with liquid wastes, such as achieving best available treatment by 1977 and best practicable treatment by 1983. In the 1980 s, this country is to have achieved "zero pollutant discharge" wherever technically feasible and economically attainable. It is now widely recognized that such an approach, while protective of the environment in most cases, would be in some cases tremendously and unnecessarily wasteful of money. Today, with greatly increased costs of energy, high rates of inflation, etc., compared to the early 1970s when the primary water pollution control legislation was passed, it is essential that money and other resources available for "pollution control" be used wisely. This does not necessarily have to be done at the expense of environmental quality. It does mean, however, that rather than universally applying ultraconservative regulations which assume that worst case conditions are present in every situation, or applying regulations that, while expedient, are not technically valid, technically sound judgment must be used to evaluate the actual 
potential impact of a contaminant in a particular situation. While the site-specific approach may not be as administratively convenient, it will promote the development of cost-effective, technically sound. environmentally protective environmental management programs, saving money, yet affording environmental protection.

It is unlikely that governmental agencies will be given adequate funding to conduct sitespecific evaluations of the potential hazards of particular solid waste-associated contaminants to the beneficial uses of water, air, soil, etc. in the region of disposal. Therefore, it is imperative that either the producer or those responsible for disposal of such wastes, or both, be given the opportunity to do the kinds of studies necessary to evaluate the actual potential hazards that a contaminant, or combination of contaminants, poses to the environment and man, on a site-specific basis. Such provisions will require that industry, municipalities, and others spend considerably greater amounts of money for investigating potential hazards than they generally have been accustomed to spending in the past. If, however, this testing is done in a tiered fashion, such as that discussed by Lee and Jones [2], it is possible to maintain at a minimum the amount of testing necessary to define the real problems associated with a particular contaminant at a particular disposal site. Further, if an industry, municipality, or other source of contaminants does not wish to undertake such studies conducted in such a way as to enable governmental agency personnel to readily determine their reliability from the information provided. then the worst ease hazard assessment should be made. This assessment would assume that all of the contaminant associated with a particular solid is in a form that can be transported to surface and groundwaters in the region of the disposal site. This worst case approach is likely to prove to be much more costly for the discharger.

\section{Factors to be Considered in Developing Site-Specific Leaching Tests}

Redox Conditions - The most important factors governing the release of contaminants from solid wastes are the chemical characteristics of the leaching environment. As was true for aquatic sediment-associated contaminants [5,6], of particular concern is the oxidation-reduction characteristic of this environment. While this can be characterized to some extent by redox potential measurements of the test system, generally such measurements are not very reliable, and it has been known for many years that minor changes in redox potentials cannot be related directly to changes in chemical behavior. Basically. what needs to be described is whether the system is oxic, that is, contains dissolved oxygen, and therefore is oxidative, or whether it is reducing, which is generally characterized by the presence of hydrogen sulfide $\left(\mathrm{H}_{2} \mathrm{~S}\right)$. There will be some waste disposal practices which create a system which is at the transition between oxidative and reductive conditions, with a redox potential near zero volts. There also may be some systems, especially associated with certain types of mining wastes, in which reducing conditions may prevail, but where there may not be an $\left(\mathrm{H}_{2} \mathrm{~S}\right)$ odor because of insufficient amounts of sulfate present in the systems to serve as a source for bacterial reduction.

Generally, most waste disposal systems will contain sufficient amounts of oxidizable organic material to allow bacteria associated with them to deplete the oxygen that is present or that migrates into the system; therefore, the release of contaminants will take 
place under reducing conditions. This could lead one to believe that the hazardous waste leaching test should be conducted under anoxic conditions, unless it can be shown that anoxic conditions would not prevail at the disposal site. As discussed by Jones and Lee [6] and Lee and Jones [2], however, one should not judge the potential impact of contaminants associated with solids based on the concentrations leached under anoxic conditions. Except in a few cases, the location of concern about the impact of chemicals on beneficial uses of water is not where the system is anoxic, but rather where the system has been aerated, that is, in areas where oxygen already has been introduced into the system. This is because anoxic waters are rarely used for drinking, to support fish life, etc. At the point at which oxygen is first added to an anoxic system, there is the possibility of the oxidation of the ferrous iron to ferric iron, which rapidly precipitates as a ferric hydroxide floc scavenging many contaminants from the water. Lee [7] has discussed the significance of iron hydroxide in scavenging many trace contaminants which could have adverse effects on a variety of beneficial uses of water. Therefore, while the leaching test may be conducted under anoxic conditions, before any attempt is made to interpret the results of the tests, the system should be aerated and the soluble constituents remaining measured as well, since it is this group and their respective concentrations which can affect beneficial uses of water. The use-interpretation of these two sets of results will have to be decided according to the specific site characteristics.

In the case of the dredged sediment elutriate test, it was believed that the test system should first be mixed under anoxic conditions (to represent the anoxic sediment/water mixing during dredging-transport) immediately followed by oxic mixing (to represent the conditions encountered when the anoxic slurry is discharged to oxic waters). Experiments showed that for most contaminants, release in the N2/air system was essentially the same as that in tests mixed only with air. One cannot be certain at this time, however, that this approach would be satisfactory for the leaching test for hazardous wastes. There may be some hazardous wastes in which a markedly different contaminant release would be found in an oxic leaching test, versus one using anoxic followed by oxic mixing.

It is important in conducting an anoxic test to ensure that the system remains anoxic for a sufficient period to allow the reduction of any iron present in the system to the ferrous form. It is possible that the simple bubbling of nitrogen gas through the system, which is appropriate for the anoxic dredged sediment elutriate test, would not be adequate for the hazardous waste leaching test. In the case of the elutriate tests, the dredged sediments are essentially anoxic prior to the test, and therefore, bubbling nitrogen serves to maintain an existing condition in which the iron is already in the reduced form. Also, the whole process of dredging-disposal takes place in a short period of time (minutes to hours). With a leaching test for hazardous wastes, however, the iron may not initially be in the reduced form; simply bubbling nitrogen through the system would then not necessarily cause all the iron to be reduced. Further, the movement of contaminants through a solid waste disposal site typically occurs over considerable periods of time (years) so that a stable, anoxic, anaerobic system would be established. Unless the laboratory leaching test system is allowed to develop similar conditions, it may not properly describe the expected leaching. The test may have to incorporate a period of incubation under the 
redox conditions that exist or may be expected to exist at the disposal site to properly simulate the leaching that would occur.

As discussed by Lee [7], the age of the ferric hydroxide precipitate (floe) and whether it forms in the presence of the contaminants or was preformed, make a significant difference in the ability of the hydrous oxide to remove the contaminants from solution. The hydrous ferric oxide that is associated with oxic solid wastes will have markedly different scavenging properties than hydrous ferric oxide that is formed during the oxidation of ferrous iron in the presence of the contaminant when the leachate solution first encounters oxygen.

Without question, the most significant deficiency of the current U.S. EPA extraction procedure and the ASTM leachate test is the failure to provide proper redox control during the test. The arbitrarily selected liquid-to-solid ratio, method of agitation, etc., do not provide for a well defined redox condition. In fact, for certain types of wastes it is possible that highly variable results would be obtained under what appear to be identical conditions, since minor variations in the degree of agitation, types of solids, degree of dispersion, etc., could change the system from anoxic to oxic, and thereby greatly affect the concentrations of contaminants released during the test. The absolute minimum that should be done for both the ASTM and the U.S. EPA tests is to aerate the leachate for a period of $30 \mathrm{~min}$ after the extraction procedure is completed, to a sufficient degree so as to ensure the maintenance of oxygen at least $2 \mathrm{mg} / \mathrm{L}$ in the system (to ensure oxic conditions) during the physical separation step-filtration of the leachate solution.

If an anoxic test has been run, it is important that the filtration step also be conducted under anoxic conditions, that is, in a glove bag under a nitrogen atmosphere. Otherwise, oxidation can occur during filtration, which could alter the amount of certain contaminants in solution.

Other Factors - A variety of other test conditions must be defined and evaluated for any specific solid waste disposal situation. The U.S. EPA has proposed the use of dilute acetic acid $\left(\mathrm{C}_{2} \mathrm{H}_{4} \mathrm{O}_{2}\right)$ as the leaching medium, based on an assumption of co-disposal with municipal solid wastes. This would be appropriate, however, only for those sites in which the hazardous materials will come in contact with a dilute $\mathrm{C}_{2} \mathrm{H}_{4} \mathrm{O}_{2}$ solution or its equivalent. The leaching solution used must have leaching properties similar to those of the leaching liquids present at the disposal area.

Depending on the solid, liquid, and contaminant, the liquid-to-solid ratio used in a leaching test may affect the amount of contaminants released. For example, the elutriate test was designed to simulate the liquid-to-solid ratios, the degree of slurrying-mixing, etc., that is typical of hydraulic dredging. However, an appreciable part of the dredging in the United States is accomplished using a clam shell dredge or other "mechanical" means, in which there is no slurrying of the sediments. Lee et al. [5] developed a modified elutriate test called the "plop test" to simulate the physical conditions encountered during mechanical dredging-disposal, in which a fairly cohesive mass of sediment (such as would be found on a barge that had been filled with sediments dredged by mechanical 
means) is dumped into the receiving waters. In general. the plop test caused much less contaminant release than the slurry-elutriate test. This would be expected, since the amount of sediment/water contact in the plop test (and mechanical dredging-disposal) is substantially less than in the elutriate test (and hydraulic dredging).

For most solid waste disposal sites, it will be difficult to define the appropriate ratio to use in laboratory testing. Rather than using an arbitrary ratio, such as automatically using the 80 percent figure used in the elutriate test for dredged sediment, a series of tests incorporating a range of ratios representative of the disposal area should be run. This will not only give an expected range of release expected, but also define the sensitivity of the test to this parameter.

The time allowed for sediment/leaching solution contact, the degree-method of mixing, the $\mathrm{pH}$, temperature, and organic content of the sediment, as well as the method of separation of the liquid and solid components following leaching, must be evaluated for solid waste leaching tests. The test conditions used must be established as appropriate for each site being evaluated. Additional discussion of the factors that must be considered in leaching tests is provided by Lee and Jones [2].

The development of a technically valid leaching test is extremely difficult at this time because no studies have been conducted to characterize hazardous waste disposal sites in terms of expected liquid-to-solid ratios, leachate characteristics, etc. One of the highest priorities for funding should be a series of appropriately designed studies to determine such characteristics for a wide variety of disposal conditions. Once information of this type is available, it will be possible to design a leaching test to simulate properly actual disposal site conditions.

\section{Interpretation of Results of Solid Waste Leaching Test}

The arbitrary approach recommended by the U.S. EPA for interpretation of its extraction procedure results is another significant deficiency in the current RCRA regulations. This approach assumes a contaminant attenuation factor of 100, that is that the concentration of of a contaminant from the solid waste will be reduced by a factor of 100 within the disposal area system, so that if the concentration in the leachate is more than 100 times the U.S. EPA drinking water standard in the test leachate, then the waste is considered hazardous. This assumption is not justifiable as a general case. Each disposal site has its own set of characteristics which determines the potential for contaminants released from the hazardous wastes to impair beneficial uses of surface and groundwaters. In some instances a factor of 100 attenuation would be too liberal an estimate; in others, it would be far too strict. Some chemicals show attenuation factors approaching infinity, while others show little attenuation. Further, attenuation properties exhibited by a chemical or mixture of chemicals at one location could be substantially different at another location, depending on such factors as the geology and hydrology of the area. As discussed by Lee and Jones [2], the U.S. EPA should provide general guidance on how the operator of a hazardous waste disposal site or the generator of the waste disposed of at a site, or both, should evaluate on a site-specific, compound (or group of compounds)-specific basis, the 
potential hazards to the environment, both surface and ground-waters, and to man. This guidance should be in the tiered-testing hazard assessment form, similar to the screening procedure for chemicals for environmental impact being developed for use in complying with the U.S. EPA Toxic Substances Control Act (TSCA) [8,9].

A hazard assessment for hazardous wastes must consider such factors as the type and amount of contaminants released from the solid waste or associated liquids, the load and rate of transport from a disposal site to a potential site of concern, the concentrations of contaminants, the forms of contaminants at the point of concern, and other related factors needed to describe the aqueous environmental chemistry of the contaminants on a sitespecific basis. In addition. potential interactions between the wastes disposed of and the disposal area materials must be investigated. Green et al. $[10,11]$ found in laboratory tests with compacted clay-soils of the type that would be used to line hazardous waste disposal pits, that a number of organic solvents, notably xylene $\left(\mathrm{C}_{8} \mathrm{H}_{10}\right)$ and carbon tetrachloride $\left(\mathrm{CCL}_{4}\right)$, caused certain clays to contract, allowing the solvent to run through the liners. While companion field studies of the impact of organic solvents on clay-soils have not yet been conducted, based on laboratory studies, this phenomenon could have serious implications for establishing "safe" disposal areas for hazardous chemicals.

The hazard assessment approach has been discussed in detail by Lee et al. $[12,13]$ who stressed the importance of making hazard assessments through tiered testing. The degree of refinement of the hazard assessment is determined by the potential hazard associated with the disposal of a particular chemical at a particular site, such that highly innocuous and highly hazardous contaminants can be identified with simple screening tests, reserving the higher, more sophisticated tests for those contaminants with intermediate potential impact. In making the decision to continue testing to better define the potential hazard, the costs of not disposing of a solid waste in the manner being evaluated must be weighed against the costs of the additional testing, which increase with increasing sophistication.

The results of a hazard assessment must be used with other information, such as the uses of the waterbody or waterbodies threatened, as well as economic factors, to make a decision regarding the suitability of a site for the disposal of the particular waste. Certainly, less stringent control programs can be allowed for certain situations in which the groundwaters that receive the leachate of the hazardous wastes do not surface, and are not used for either domestic or industrial water supplies. For example, significant amounts of groundwaters in some parts of the country are highly saline, and therefore are of limited value for domestic water supplies, agriculture, irrigation, etc. However, it is important to recognize that groundwaters, once contaminated, are extremely difficult to reclaim, much more difficult than most surface waters.

Because of the extremely limited research funding that has been made available by the U.S. EPA in groundwater chemistry research, it is going to be very difficult to conduct proper hazard assessment with the information currently available. It is obvious that if technically valid, cost-effective programs are to be developed for management of hazardous wastes to protect groundwater systems, a significant increase will be necessary 
in research funding provided by industries and their associations, municipalities, and state and federal governmental agencies devoted to the aqueous environmental chemistry of a wide variety of contaminants in groundwater systems. Particular attention in this area will have to be given to sorption reactions, since this type of reaction probably will be the most important in causing attenuation or alteration, or both, of the contaminants released from a particular hazardous waste disposal site to and through groundwaters.

\section{Considerations for Permitting Hazardous Waste Disposal Sites}

The permitting of hazardous waste disposal sites should include several facets not now required. First, all permits for hazardous waste disposal sites should include a hazard evaluation of the type that is discussed in this paper and described in detail by Lee and Jones [2]. Since, in accord with the provisions of RCRA, hazardous wastes in small amounts can be disposed of at municipal landfills, all municipal landfills also should be required to have hazard assessments conducted for their wastes. It is important to emphasize that all chemicals have some hazard associated with them. The actual threat that a chemical poses to man and the environment depends on its concentration and the duration of exposure of organisms of concern. For example, sodium chloride $(\mathrm{NaCl})$, which generally is thought to be innocuous, can have a significant detrimental effect on the environment and man, if they are exposed to sufficiently high concentrations for sufficiently long durations. It is inappropriate to classify wastes or leachates as hazardous based solely on the concentrations released in a simple test. What must be done is to consider, as described above, the behavior in the particular aquatic systems of concern potentially impacted by the disposal site.

The U.S. EPA's groundwater monitoring program that must be carried out as part of the operation of hazardous waste disposal sites in accord with the provisions of RCRA, will provide extremely valuable information for improving the reliability of the hazard assessments that are being made. There are significant deficiencies in the information base currently available on various components of hazard assessment for solid waste disposal sites, especially the environmental chemistry of contaminants in groundwater and disposal site situations. However, through comparisons of the results of hazard assessments made as part of permitting the site, with what is actually transported from the site to groundwaters as measured in monitoring wells located at appropriate distances down-groundwater gradient from a disposal site, the information needed to significantly improve the reliability of future hazard assessments will be obtained.

\section{Acknowledgments}

Support for preparation of this paper was provided by G. Fred Lee and AssociatesEnviroQual, Fort Collins, Colo.

\section{References}

[1] Lee, G. F., "Comments on December 19, 1978 Federal Register, 'Guidelines for Hazardous Waste Management,"' Occasional Paper No. 39, Department of Civil 
Engineering, Environmental Engineering Program, Colorado State University, Fort Collins, Colo., 1979.

[2] Lee, G. F. and Jones, R. A., in Environmental Risk Analysis for Chemicals, R. Conway, Ed., Van Nostrand Reinhold, New York, 1982, pp. 529-549.

[3] Lee, G. F., personal communication to E. R. Sullivan, Staff Manager, ASTM Committee D-19, Philadelphia, Pa. 16 Jan. 1980.

[4] Lee, G. F. "Factors Affecting the Transfer of Materials Between Water and Sediments," Eutrophication Information Program. Literature Review No. 1, University of Wisconsin-Madison, 1970.

[5] Lee, G. F., Jones, R.A., Saleh, F.Y., Mariani, G. M., Homer. D. H., Butler. J. S., and Bandyopadhyay, P, "Evaluation of the Elutriate Test as a Method of Predicting Contaminant Release during Open Water Disposal of Dredged Sediment and Environmental Impact of Open Water Dredged Materials Disposal, Vol. II: Data Report," Technical Report D78-45. U.S. Army Corps of Engineers Waterways Experiment Station, Vicksburg, Miss., 1978.

[6] Jones, R.A. and Lee, G. F., "Evaluation of the Elutriate Test as a Method of Predicting Contaminant Release during Open Water Disposal of Dredged Sediment and Environmental Impact of Open Water Dredged Material Disposal, Vol. I: Discussion," Technical Report D78-45. U.S. Army Corps of Engineers Waterways Experiment Station, Vicksburg, Miss., 1978.

[7] Lee, G.F., "Role of Hydrous Metal Oxides in the Transport of Heavy Metals in the Environment," in Progress in Water Technology, Vol. 17, 1975, pp. 137-147.

[8] Cairns, J., Jr, Dickson, K.L., and Maki, A.W., Eds. Estimating the Hazards of Chemical Substances to Aquatic Life, ASTM STP 657, American Society for Testing and Materials, 1978.

[9] Dickson, K.L, Make, A.W., and Cairns, J., Jr., Eds., Analyzing the Hazard Evaluation Process, Proceedings of an International Workshop on the Application of Hazard Evaluation Programs for Chemicals in the Aquatic Environment, Waterville Valley, N.H., published by American Fisheries Society, Bethseda, Md., 1979.

[10] Green, W.J., Lee, G. F., and Jones, R. A., " Impact of Organic Solvents on the Integrity of Clay Liners for Industrial Waste Disposal Pits: Implication for Groundwater Contamination," Report to U.S. EPA Robert S. Kerr Environmental Laboratory, Ada, Okla., 1980.

[11] Green, W. J., Lee, G. F., and Jones, R.A. Journal of Water Pollution Control Federation, Vol. 53, 1981, pp. 1347-1354. 
[12] Lee, G. F., Jones, R.A., and Newbry, B.W., "An Environmental Hazard Assessment Approach for Water Quality Management," Occasional Paper No. 4b, Department of Civil Engineering, Environmental Engineering Program, Colorado State University, Fort Collins, Colo, 1979.

[13] Lee, G. F., Jones, R. A., and Newbry, B.W., "Alternative Approach to Assessing Water Quality Impact of Wastewater Effluents," Proceedings Industrial Waste Symposium, Water Pollution Control Federation, Las Vegas, Nev., 1980.

Editors' note: Work by others on leaching and extraction procedures has been reviewed by C. L. Perket and W. C. Webster in their contribution to this publication; their review should be consulted for additional information on this topic.

The italic numbers in brackets refer to the list of references appended to this paper.

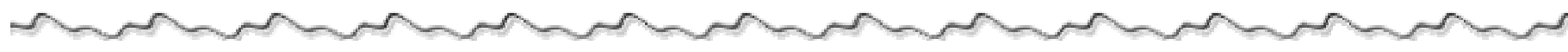

Reference as: "Lee, G.F. and Jones, R.A., 'Application of Site-Specific Hazard Assessment Testing to Solid Wastes,' In: Hazardous Solid Waste Testing, ASTM STP 760. R. American Society for Testing and Materials, pp. 331-344, (1981)." 